\title{
SATB1 Promotes Pancreatic Cancer Growth and Invasion Depending on MYC Activation
}

\author{
Zheng Chen ${ }^{1,2} \cdot$ Zengliang $\mathrm{Li}^{1,2,3,4} \cdot$ Wei $\mathrm{Li}^{1,5} \cdot$ Yang Zong ${ }^{1,2,6} \cdot$ Yi Zhu ${ }^{1,2}$. \\ Yi Miao ${ }^{1,2} \cdot$ Zekuan $\mathrm{Xu}^{1,2}$
}

Received: 12 March 2015/Accepted: 10 June 2015/Published online: 25 June 2015

(C) The Author(s) 2015. This article is published with open access at Springerlink.com

\begin{abstract}
Background SATB1 plays an important role in human malignant progression, inducing cancer cell proliferation and metastasis by regulating downstream gene expressions. However, little is known about the underlying mechanisms in which SATB1 promotes pancreatic cancer tumorigenesis.

Aims To investigate SATB1 expression levels and its biological functions in promoting pancreatic cancer growth and invasion.

Methods SATB1 expression levels were detected in seven human pancreatic cancer cell lines and 16 pairs of normal pancreatic/pancreatic cancer tissues using RT-PCR and western blot. SW1990 or Capan-1 cells stably
\end{abstract}

Zheng Chen and Zengliang Li have been contributed equally to this work.

Zekuan Xu

xzkjssry@gmail.com; xuzekuan@njmu.edu.cn

Zheng Chen

czjssry@gmail.com

Zengliang $\mathrm{Li}$

lizengliang123@126.com

Wei Li

liwei10@suda.edu.cn

Yang Zong

zangy_0316@yahoo.com.cn

Yi Zhu

zhuyijssry@126.com

Yi Miao

miaoyi@njmu.edu.cn

1 Department of General Surgery, The First Affiliated Hospital of Nanjing Medical University, 300 Guangzhou Road,

Nanjing 210029, People's Republic of China knockdown (shRNA) or transiently knockdown (siRNA) SATB1 cells, and PANC-1 stably overexpressing SATB1 cells were investigated with MTT, EdU assay, flow cytometry, and transwell invasion assay for cell proliferation and invasion activity. The binding of SATB1 to MYC promoter region was examined using reporter assay. Expression of SATB1 in 68 pancreatic cancer samples was studied by immunohistochemical staining and scoring.

Results SATB1 was overexpressed in pancreatic cancer tissues samples, showing strong correlation with pancreatic cancer invasion depth and tumor staging. SATB1 induced MYC mRNA and protein expression; promoted pancreatic cancer cell growth; increased cell population in S phase; and enhanced pancreatic cancer cell invasion in vitro. On the other hand, SATB1 knockdown showed opposite effects. Furthermore, MYC blocking in SATB1-

2 Institute of Tumor Biology, Jiangsu Province Academy of Clinical Medicine, Nanjing, People's Republic of China

3 Department of Gastrointestinal Surgery, Huai' an First People's Hospital, Nanjing Medical University, 6 Beijing Road West, Huai'an 223300, People's Republic of China

4 Department of General Surgery, Huai' an First People's Hospital, Nanjing Medical University, Huai'an, People's Republic of China

5 Department of Oncology, The First Affiliated Hospital of Soochow University, No. 1, Shizi Street, Suzhou City 215006, People's Republic of China

6 Department of General Surgery, Changshu No. 1 People's Hospital, 1 Shuyuan Street, Changshu 215500, People's Republic of China 
overexpressing cells attenuated the promotion of pancreatic cancer cell growth and invasion. Our data also indicated that SATB1 bound to specific promoter region of MYC.

Conclusions SATB1 is overexpressed in pancreatic cancer, promoting cancer cell proliferation and invasion through the activation of MYC.

Keywords Special AT-rich binding protein $1 \cdot$ Pancreatic carcinoma Cell cycle $\cdot$ Myelocytomatosis viral oncogene

$\begin{array}{ll}\text { Abbreviations } \\ \text { SATB1 } & \text { Special AT-rich binding protein 1 } \\ \text { MYC } & \text { Myelocytomatosis viral oncogene } \\ \text { MARs } & \text { Matrix attachment regions } \\ \text { DMSO } & \text { Dimethyl sulphoxide } \\ \text { PBS } & \text { Phosphate-buffered saline } \\ \text { DMEM } & \text { Dulbecco's minimum essential medium } \\ \text { FBS } & \text { Fetal bovine serum } \\ \text { ELISA } & \text { Enzyme-linked immunosorbent assay } \\ \text { PI } & \text { Propidium iodide } \\ \text { FACS } & \text { Fluorescence-activated cell sorter } \\ \text { PVDF } & \text { Polyvinylidene fluoride } \\ \text { ECL } & \text { Chemiluminescent } \\ \text { EdU } & \text { 5-Ethynyl-2'-deoxyuridine } \\ \text { BURs } & \text { Base-unpairing regions }\end{array}$

\section{Background}

Pancreatic cancer is the fifth leading cause of cancer death in Japan [1], the sixth leading cause of cancer death in China, and the fourth leading cause of cancer death in the USA [2]. Due to a lack of obvious symptoms during the early stages of pancreatic cancer, very few patients receive an early diagnosis, and most are not diagnosed until they reach the late stages of this disease. To further exacerbate the issue, advanced local disease or distant metastases prevent the majority of pancreatic cancer patients with a definitive diagnosis from responding to nearly all of the present treatments [3]. The limitations associated with its diagnosis and treatment make the mortality rate of pancreatic adenocarcinoma the highest among all cancers [4]. However, in patients who are suitable for resection, 5-year survival rates of approximately $5 \%$ are observed, providing evidence that surgery and subsequent chemical therapy offer the only chance of a potential cure and long-term survival $[5,6]$. Better understanding of the changes that occur at the gene and protein levels during pancreatic cancer progression will bring better prognosis to patients.

Chromatin architecture plays an important role in the regulation of nuclear function. Matrix attachment regions
(MARs) are specialized genomic sequences that show a high affinity for the nuclear matrix and are able to tether chromatin loops in vivo [7, 8]. MARs form specific binding sites on the minor grove of AT-rich DNA for proteins that recognize DNA structure, rather than specific DNA sequences [9]. At present, several proteins have been identified that bind to MARs, including the special AT-rich binding protein 1 (SATB1) [10]. SATB1 is found predominantly in thymocytes, and it regulates gene expression by folding chromatin into loop domains, tethering specialized DNA elements to an SATB1 network structure $[11,12]$. The overexpression of SATB1 has recently been found in many different kinds of human tumors including breast cancer, gastric cancer, and rectal cancer [13-15], promoting cancer cell invasion and metastasis [16, 17]. SATB1 expression level also shows strong correlation with the progression of rectal cancer [18], and it is an independent prognostic marker for gastric cancer [19]. However, the role of SATB1 in pancreatic cancer development and progression is still unknown.

The proto-oncogene MYC ( $\mathrm{v}-\mathrm{myc}$ avian myelocytomatosis viral oncogene homolog) encodes a nuclear phosphoprotein transcription factor that regulates a large number of genes involved in many critical cellular functions including proliferation, cell cycle progression, differentiation, and apoptosis [20-22]. Amplification of MYC has been reported in different kinds of human cancers [2326]. The overexpression of MYC is observed in more aggressive breast cancer and correlates with poor prognosis and distant metastasis [27, 28], but the biological function of MYC in pancreatic cancer progression has yet to be fully understood.

Matrix metalloproteinase (MMP) family is involved in the breakdown of extracellular matrix in normal physiological processes as well as in pathological processes, such as arthritis and tumor metastasis [29-31]. MMP2 and MMP9 are important members of MMP family, promoting cancer cell angiogenesis, invasion, and metastasis [32, 33]. Recently, a study has shown that both MMP2 and MMP9 were induced after the overexpression SATB1 in breast cancer [16], but the exact mechanism is unknown.

The primary objective of this study was to investigate the role of SATB1 in promoting pancreatic cancer proliferation and invasion and identifying the underlying molecular mechanism. We have uncovered the overexpression of SATB1 in pancreatic cancer tissues compared with adjacent normal samples. We have demonstrated that SATB1 regulates pancreatic cancer proliferation, cell cycle progression, and invasion through the activation of MYC. We also have shown strong correlation between SATB1 expression and pancreatic cancer tumor invasion depth and staging. These novel findings underscore the important role of SATB1 in promoting pancreatic cancer tumorigenesis 
and the potential therapeutic target of SATB1 in pancreatic cancer.

\section{Methods}

\section{Cell Culture and Reagents}

Human pancreatic cancer cell lines, including PANC-1, SW1990, CFPAC-1, BxPC-3, HPAC, MIAPaCa-2, and Capan-1, were purchased from the American Type Culture Collection (Manassas, VA, USA) and maintained in DMEM (Gibco, Grand Island, NY, USA) supplemented with $10 \%$ fetal bovine serum (FBS), 100 units/ml penicillin, and $100 \mathrm{mg} / \mathrm{ml}$ streptomycin (Gibco). The cultures were incubated at $37{ }^{\circ} \mathrm{C}$ in a humidified atmosphere with $5 \% \mathrm{CO}_{2}$. Cells were passaged every 2-3 days to support exponential growth. SATB1, MMP2, MMP9, MYC and $\beta$-actin antibodies, SATB1 siRNA, and MYC siRNA were purchased from Santa Cruz Biotechnology (Santa Cruz, CA, USA). Horseradish peroxidase (HRP)-conjugated mouse and goat secondary antibodies were purchased from Genscript (Nanjing, China).

\section{Specimen Collection and Ethics Statement}

Sixteen pairs of human primary pancreatic carcinomas and adjacent normal pancreatic tissue samples and 68 formalinfixed paraffin-embedded pancreatic cancer tissue samples were surgically removed and snap-frozen in liquid nitrogen or fixed in $10 \%$ formalin and embedded in paraffin; these tissues samples were obtained from fresh pancreaticoduodenectomy (Whipple resection) or from the body and tail of pancreas resections, along with pathology summaries at the Department of General Surgery of the First Affiliated Hospital of Nanjing Medical University between 2006 and 2009. Pancreatic cancer staging was followed the guideline as we described before [34]. All human tissue samples were obtained according to the ethical guidelines of the Declaration of Helsinki. This study was approved by Ethics Committee of Nanjing Medical University. All patients participated after having provided informed consent. Tumor stage was evaluated in accordance with the tumornode metastasis (TNM) classification system UICC/AJCC 2002.

\section{SATB1 Knockdown or Overexpression and MYC Knockdown}

SATB1 shRNA was designed based on the SATB1 mRNA sequence [GenBank: NM_002971] with BLOCK-iT ${ }^{\mathrm{TM}}$ RNAi Designer (Invitrogen Life Technologies, Carlsbad, CA, USA): SATB1-shRNA oligoduplexes (5'-
GGATTTGGAAGAGAGTGTC-3' ${ }^{\prime}$ ) were synthesized and cloned into pGCsi-H1/Neo/GFP (Genechem, Shanghai, China). Pancreatic cancer cell line SW1990, which expresses high level of endogenous SATB1, was transfected with pGCsi-H1/Neo/GFP-SATB1-shRNA or empty vector using Lipofectamine 2000 (Invitrogen Life Technologies) following the manufacturer's instruction. Fortyeight hours later, the transfected cells were selected and maintained in media containing $800 \mu \mathrm{g} / \mathrm{ml} \mathrm{G} 418$ (Invitrogen Life Technologies). The full-length SATB1 coding sequence (CDS) was cloned into pcDNA3.1 mammalian expression construct (Invitrogen Life Technologies) defining as pcDNA3.1-SATB1. Pancreatic cancer cell line PANC-1 expressing low level of endogenous SATB1 was transfected with pcDNA3.1-SATB1 or empty vector using Lipofectamine 2000 (Invitrogen Life Technologies) following the manufacturer's instruction. PANC-1 cells stably expressing SATB1 or empty vector was selected and maintained in media containing $600 \mu \mathrm{g} / \mathrm{ml} \mathrm{G418.} \mathrm{SATB1}$ siRNA was transfected using RNAifectin ${ }^{\mathrm{TM}}$ transfection reagent (Applied Biological Materials Inc, Richmond, BC, Canada) in SW1990 or Capan-1 cells with relative high levels of SATB1 following manufacturer's protocol. MYC siRNA was transfected with RNAifectin ${ }^{\mathrm{TM}}$ transfection reagent (Applied Biological Materials Inc) in PANC-1 cells that stably overexpressing SATB1 and in control cells following the manufacturer's protocol to knock down MYC.

\section{Cell Growth Curves}

Cellular growth was evaluated by MTT assays. SW1990 stably knockdown, PANC-1 stably overexpressing SATB1, or control cells were seeded at a density of $1.0 \times 10^{3}$ cells/ well in 96-well plates. After cells were allowed to adhere for $2 \mathrm{~h}$, and at every $12 \mathrm{~h}$ until $96 \mathrm{~h}$, MTT (Sigma-Aldrich, St. Louis, MO, USA) was added to each well at a final concentration of $0.5 \mathrm{mg} / \mathrm{ml}$, followed by incubation at $37{ }^{\circ} \mathrm{C}$ for $4 \mathrm{~h}$. The medium was then removed, and $200 \mu \mathrm{l}$ of DMSO was added to each well. The absorbance of the mixture was measured at $490 \mathrm{~nm}$ using a microplate ELISA reader (Bio-Rad Laboratories, Hercules, CA, USA). The relative cell number was calculated using the following equation: relative cell number $=$ mean experimental absorbance/mean 2-h absorbance.

\section{Cell Cycle Analysis}

SW1990 stably expressing SATB1 shRNA or empty vector cells were incubated in six-well plates $\left(5 \times 10^{4}\right.$ cells/well $)$. Forty-eight hours later, cells were fixed with $80 \%$ chilled ethanol and then incubated with $0.5 \%$ Triton X-100 solution containing $1 \mathrm{mg} / \mathrm{ml}$ RNase A (Qiagen, 
Germantown, MD, USA) at $37^{\circ} \mathrm{C}$ for $30 \mathrm{~min}$. Propidium iodide (PI) (Sigma) was added to each well at a final concentration of $50 \mu \mathrm{g} / \mathrm{ml}$ later, followed by a $30-\mathrm{min}$ incubation in the dark. Cellular DNA content was analyzed using a FACS machine (Becton-Dickinson, Franklin Lakes, NJ, USA). Data were processed using WinMDI29 software (Becton-Dickinson).

\section{Cell Migration and Invasion Assays}

Cell migration and invasion assays were performed using $24-w e l l$ transwell plates ( 8 - $\mu$ m pore size) from Sigma. In the invasion assays, Matrigel (BD Biosciences, Morrisville, NC, USA) was diluted to $1 \mathrm{mg} / \mathrm{ml}$ in serum-free, cold DMEM, and $100 \mu \mathrm{l}$ of the diluted Matrigel was added to each insert chamber. The plates were incubated at $37^{\circ} \mathrm{C}$ for $4 \mathrm{~h}$ to allow gelling. SW1990 stably knockdown, PANC-1 stably overexpressing SATB1, or control cells were harvested from culture plates and re-suspended in serum-free culture medium at a density of $10^{5}$ cells $/ \mathrm{ml}$. After collecting the cell samples, $100 \mu \mathrm{l}$ of the cell suspension was added into each insert chamber. The lower chamber was filled with $600 \mu \mathrm{l}$ of culture media containing $10 \%$ FBS. After $24 \mathrm{~h}$ of incubation, non-invading cells on the top of the membrane were removed using cotton swabs. Invaded cells on the bottom of the membrane were fixed with $4 \%$ paraformaldehyde for $15 \mathrm{~min}$, followed by staining with $0.05 \%$ crystal violet for $2 \mathrm{~h}$. Photographs were taken, and all the cells on the entire membrane were counted. The relative invasion activity was calculated after normalization to cell migration.

\section{RT-PCR and Quantitative Real-Time PCR}

Total RNA was extracted from cancer cell lines using Trizol reagent (Invitrogen Life Technologies). Total RNA (1 $\mu \mathrm{g})$ was reverse-transcribed by A3500 AMV RT-PCR (reverse transcription polymerase chain reaction) system (Promega, Madison, WI, USA). The products of the PCR were electrophoresed on $1 \%$ agarose gels, visualized by ethidium bromide staining and quantified using Quantity One software (Bio-Rad, Hercules, CA, USA). The results were analyzed using SDS 2.3 software (Invitrogen Life Technologies). $\beta$-Actin was used as the internal positive control and reference gene for the normalization of PCR cycle numbers to ensure a linear amplification of templates in each experiment. The quantitative real-time PCR was performed and analyzed in a 7900HT (Invitrogen Life Technologies) using SYBR Green Real-time PCR Master Mix (TOYOBO, Shanghai, China).

\section{Western Blotting}

Total protein was extracted using a lysis buffer containing $50 \mathrm{mM}$ Tris- $\mathrm{HCl}$ (pH 7.4), $150 \mathrm{mM} \mathrm{NaCl}, 1 \%$ Triton
$\mathrm{X}-100,0.1 \%$ SDS, and $1 \mathrm{mM}$ EDTA supplemented with protease inhibitors and phosphatase inhibitors provided by Sigma. The protein extract was loaded, size-fractionated by SDS-polyacrylamide gel electrophoresis, and transferred to PVDF membranes (Bio-Rad). After blocking, the membranes were incubated with primary antibodies at $4{ }^{\circ} \mathrm{C}$ overnight. Membranes were probed with specific antibodies, and proteins were visualized by using HRP-conjugated secondary antibodies and Immobilon Western Chemiluminescent HRP Substrate Detection Reagent (Millipore, Billerica, MA, USA). Gel loading was normalized for equal $\beta$-actin.

\section{EdU Cell Proliferation Assay}

Cell proliferation was evaluated using the ClickiT $^{\circledR}$ EdU (5-ethynyl-2'-deoxyuridine) assay (Invitrogen Life Technologies), which measures actively proliferating cells. EdU is incorporated as thymidine analog in the DNA of newly dividing cells and is detected by a copper-catalyzed reaction with Alexa Fluor 594 dye (red fluorescence). SW1990 stably knockdown, PANC-1 stably overexpressing SATB1, or control cells $\left(1.5 \times 10^{4}\right)$ were cultured in 8 -well culture slides for $48 \mathrm{~h}$. EdU labeling was done by incubating cells with $10 \mu \mathrm{M}$ EdU solution prepared in pre-warmed complete medium at $37{ }^{\circ} \mathrm{C}$ in an atmosphere containing $5 \%$ $\mathrm{CO}_{2}$ for $1 \mathrm{~h}$. Next, cells were fixed in $3.7 \%$ paraformaldehyde solution prepared in $1 \times$ PBS for $15 \mathrm{~min}$ at room temperature followed by two washes with $3 \%$ BSA in PBS. Then, cells were permeabilized by treating with permeabilization buffer $(0.5 \%$ Triton X-100 in PBS) for $20 \mathrm{~min}$. After rinsing the cells with wash solution, cells were incubated with $1 \times$ ClickiT $^{\circledR}$ reaction cocktail containing ClickiT $^{\circledR}$ reaction buffer, CuSO4 solution, 1× ClickiT $^{\circledR}$ reaction buffer additive, and Alexa Fluor 594 dye for $30 \mathrm{~min}$ at room temperature in a dark humidified chamber. Before visualizing under a fluorescence microscope (Olympus Co., Tokyo, Japan) at $40 \times$ magnification, cells were washed twice with $3 \%$ BSA in PBS and the nuclei are counterstained with blue fluorescent Hoechst 33342. All experiments were performed in triplicate, and 500 cells were counted from each experiment. The percentage of cells with nuclear EdU staining was calculated and graphed.

\section{Evaluation of Immunohistochemical Staining and Scoring}

Patterns of staining, staining intensities, and percentages of SATB1-expressing cells in 68 pancreatic cancer tissue samples were recorded. The staining patterns were evaluated using the immunoreactive score (IRS) recommended by Stegner [35]. In this scoring system, IRS = SI (staining 
intensity) $\times$ PP (percentage of positive cells). SI was defined as 0 , negative; 1 , weak; 2 , moderate; and 3 , strong. PP was determined as $1,0-9 \%$ positive cells; $2,10-50 \%$ positive cells; and $3,>50 \%$ positive cells. One hundred cells were counted in each of ten $40 \times$ visual fields from different areas of each random section chosen for IRS evaluation. Then, the average IRS was calculated for each sample. The intensity of SATB1 staining was defined as "negative" or "positive," corresponding to IRS values below 1 or above 1 , respectively. Sample sections were reviewed and scored by two researchers including one pathologist.

\section{Dual-Luciferase Reporter Assay}

Thirteen different lengths of MYC $5^{\prime}$ promoter regions $(-3090$ to +100$)$ were cloned into pGL3 luciferase reporter vector (Promega, Madison, WI, USA) and defined as pGL3-R1 to R13. SW1990 stably knockdown SATB1 or control cells in 24-well plates were transfected with $100 \mathrm{ng}$ of pGL3-R1 to R13 and $50 \mathrm{ng}$ of normalization plasmid pRL-TK Renilla. The dual-luciferase reporter assay was performed $48 \mathrm{~h}$ after transfection using a luciferase assay system (Promega). Activities were normalized to pRL-TK activity and further normalized to pGL3-basic group.

\section{Statistical Analyses}

Each experiment was performed at least in triplicate. PCR results were analyzed using Quality One software (BIORAD). Statistical analyses were performed using SPSS 13.0. MTT, migration/invasion, EdU, promoter reporter, qRT-PCR assays, and growth curve analysis in cells were assessed using the two-tailed Student's $t$ test, MannWhitney $U$ test, or one-way ANOVA. The Chi-squared test was used to compare categorical groups. A $P$ value less than 0.05 was considered significant.

\section{Results}

\section{SATB1 Is Overexpressed in Human Pancreatic Cancer Cell Lines and Tissue Samples}

The PCR and western blot data demonstrated that SATB1 mRNA and protein were expressed in six human pancreatic cancer cell lines: MIAPaCa-2, BxPC-3, HPAC, CFPAC-1, Capan-1, and SW1990 (Fig. 1a, b). At the same time, our results indicated that SW1990 expressed highest level of endogenous SATB1 in seven pancreatic cancer cell lines, while PANC-1 with relative low level of SATB1 mRNA or protein (Fig. 1b). We next examined SATB1 mRNA and protein expression level in 16 pairs of human pancreatic cancer and adjacent normal pancreatic tissue samples using RT-PCR or western blot. The results demonstrated that SATB1 mRNA was overexpressed in pancreatic cancer samples compared with normal tissue (Fig. $1 \mathrm{c}, P<0.05$ ), whereas $87.5 \%$ (14 out of 16) cancer samples expressed higher SATB1 protein level than adjacent normal tissue samples (Fig. 1d, left panel). The quantification data showed significantly higher levels of SATB1 expressed in pancreatic cancer tissue samples compared with normal pancreas (Fig. 1d, right panel, $P<0.001$ ). These results suggested that SATB1 is frequently overexpressed in human pancreatic cancer.

\section{SATB1 Promotes Pancreatic Cancer Cell Proliferation and Invasion}

Previous studies have shown that the overexpression of SATB1 increased breast cancer cell proliferation and metastasis [16]. Therefore, to investigate whether the overexpression of SATB1 in pancreatic cancer promotes cell proliferation and invasion, we evaluated cell growth and invasion activity using PANC-1 stably overexpressing SATB1 cells and SW1990 stably knockdown SATB1 cells. The SATB1 knockdown in SW1990 cells and overexpression in PANC-1 cells were confirmed by RT-PCR (Fig. 2a, b; left panels) and western blot (Fig. 2a, b; right panels). Cell growth curve analysis results indicated that knockdown of SATB1 in SW1990 cells (SATB1 shRNA) significantly inhibited cell proliferation compared with control cells (Control; Fig. 2c). On the other hand, SATB1 overexpression in PANC-1 (pcDNA SATB1) promoted cell growth compared with control cells (pcDNA; Fig. 2d). In line with these results, cell cycle distribution analysis demonstrated that knockdown of SATB1 in SW1990 obviously decreased the percentage of cells in $S$ phase compared with control cells (Fig. $2 \mathrm{e}, P<0.01$ ) indicating inhibition of cell growth by knockdown of SATB1. We further confirmed these results using EdU cell proliferation assay. Our data demonstrated that only $14 \%$ of SW1990 SATB1 knockdown cells were positive for nuclear EdU staining (red fluorescence), whereas $31 \%$ of control cells showed a similar staining (Fig. 3a, $P<0.001$ ). By contrast, $43 \%$ of SATB1-overexpressing PANC-1 cells displayed positive nuclear EdU staining, while only $24 \%$ of control cells were positive (Fig. $3 b, P<0.001$ ). These data strongly indicated that SATB1 promotes pancreatic cancer proliferation through regulating cell cycle progression. We next examined the role of SATB1 in regulating pancreatic cancer cell invasion ability. Transwell cell migration/invasion assay results indicated that knockdown of SATB1 in SW1990 cells significantly decreased invasive activity compared with control cells (Fig. 3c, $P<0.001$ ). On the other side, the overexpression of SATB1 in PANC-1 cells 
A

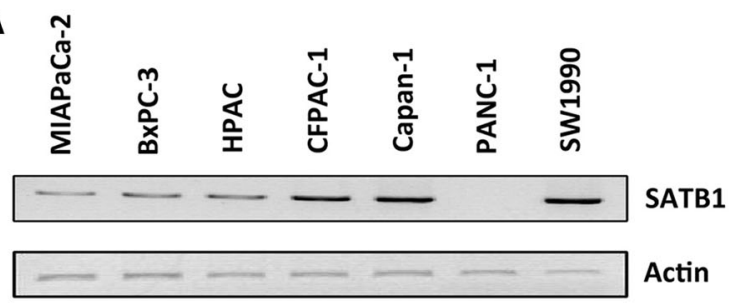

B

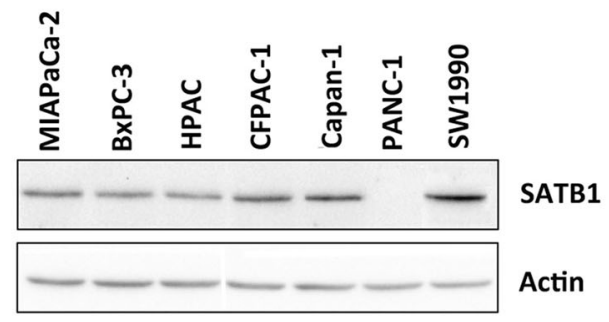

C

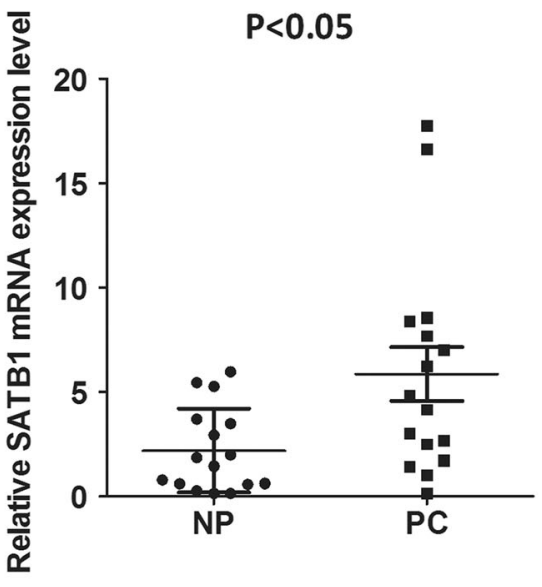

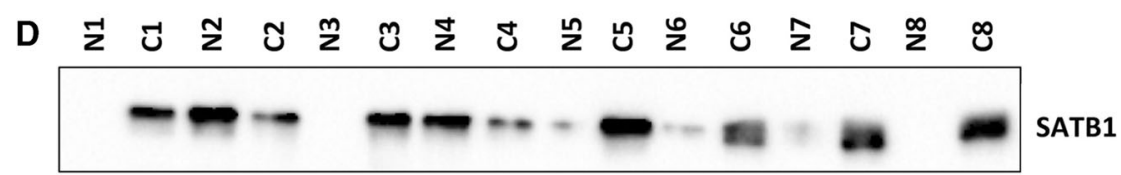
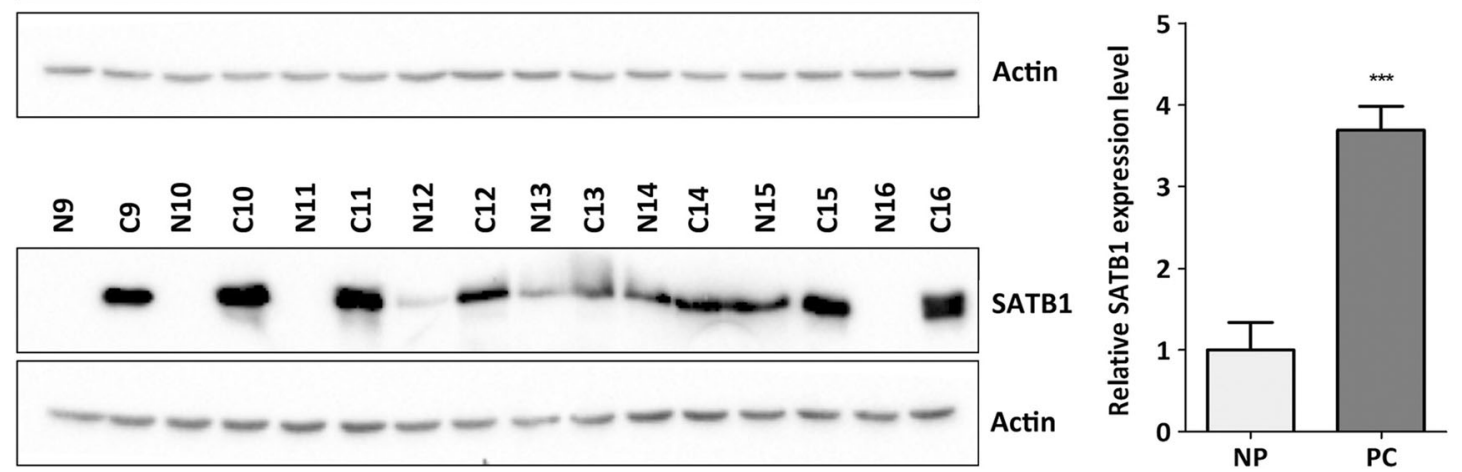

Fig. 1 Overexpression of SATB1 in pancreatic cancer cell lines and tissue samples. a PCR analysis of SATB1 mRNA expression level in seven human pancreatic cancer cell lines. b SATB1 protein expression level in pancreatic cancer cell lines. $\mathbf{c}$ Real-time PCR showing SATB1 mRNA expression level in 16 pairs of human pancreatic cancer tissue samples. Horizontal bars indicate the arithmetic mean.

strongly increased invasive activity than control cells (Fig. 3d, $P<0.001$ ). To further confirm our results, we transiently knocked down SATB1 in SW1990 and Capan-1 cells using SATB1 siRNA transfection. Our results demonstrated that SATB1 siRNA knockdown significantly deceased SATB1 protein level in SW1990 and Capan-1 cells (Fig. 4a). As expected, the transiently knockdown of SATB1 (SATB1 siRNA cells) decreased both nuclear EdU staining-positive cell number and invasion activity in SW1990 (Fig. 4b, d) or Capan-1 (Fig. 4c, e) cells compared with control. These results clearly indicated that SATB1 promotes pancreatic cancer cell proliferation and invasion.
Error bars indicate standard deviation (SD). $P<0.05$, MannWhitney $U$ test. d Western blot analysis of SATB1 protein expression level in 16 pairs of human pancreatic cancer $(\mathrm{C})$ or normal pancreas tissue $(\mathrm{N})$ samples. e Quantification data of panel $(\mathbf{d}) * * * P<0.001$, $t$ test

\section{SATB1 Regulates MYC and MMP9 in Pancreatic Cancer Cells}

To investigate the underlying mechanisms by which SATB1 promotes pancreatic cancer proliferation and invasion, we examined MYC and MMP9 mRNA and protein expression levels in SATB1 overexpression or knockdown cells. Our data indicated that the stably knockdown of SATB1 in SW1990 cells significantly decreased the mRNA and protein levels of MYC and MMP9 compared with control cells (Fig. 5a). On the other hand, PANC-1 SATB1-overexpressing cells induced more MYC and MMP9 mRNA or protein levels than control cells (Fig. 5b). These data clearly 
A

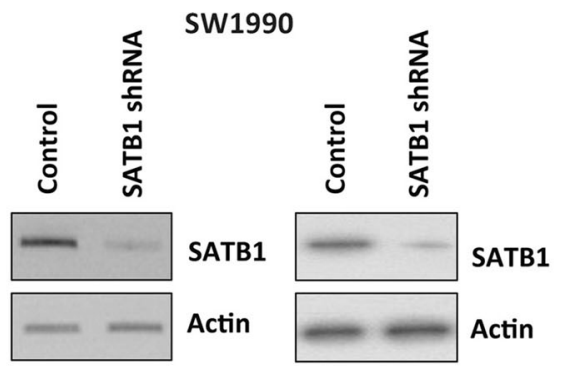

C

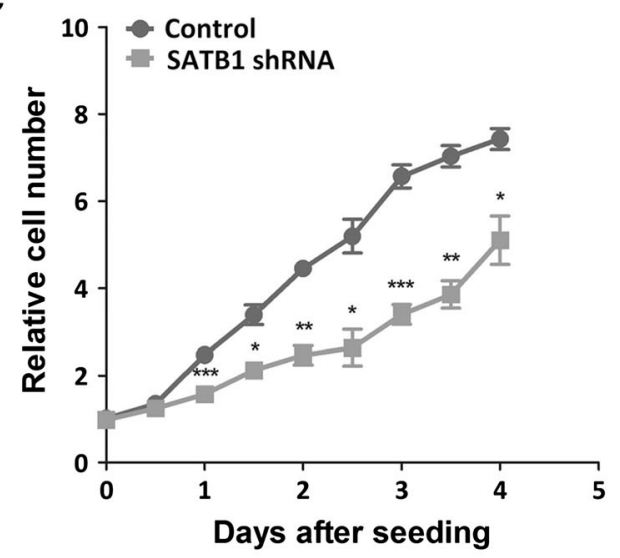

E

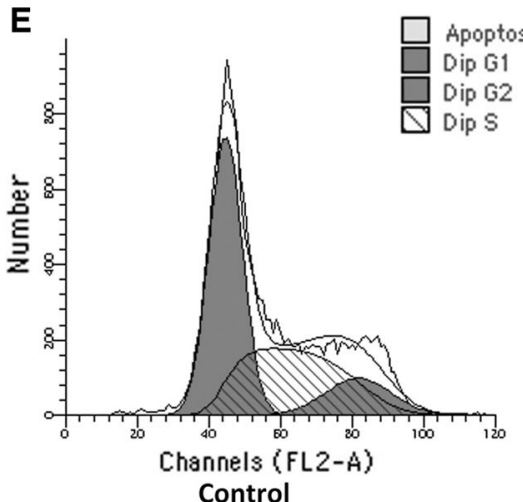

Control
B

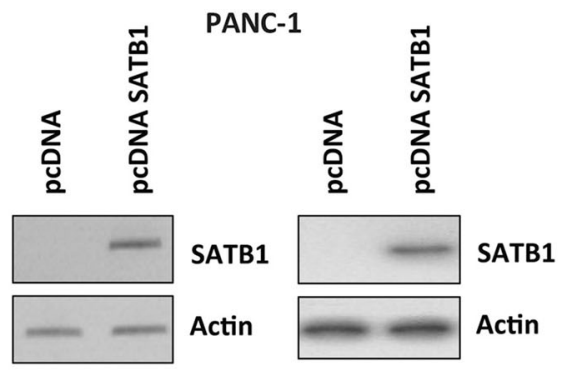

PANC-1

D
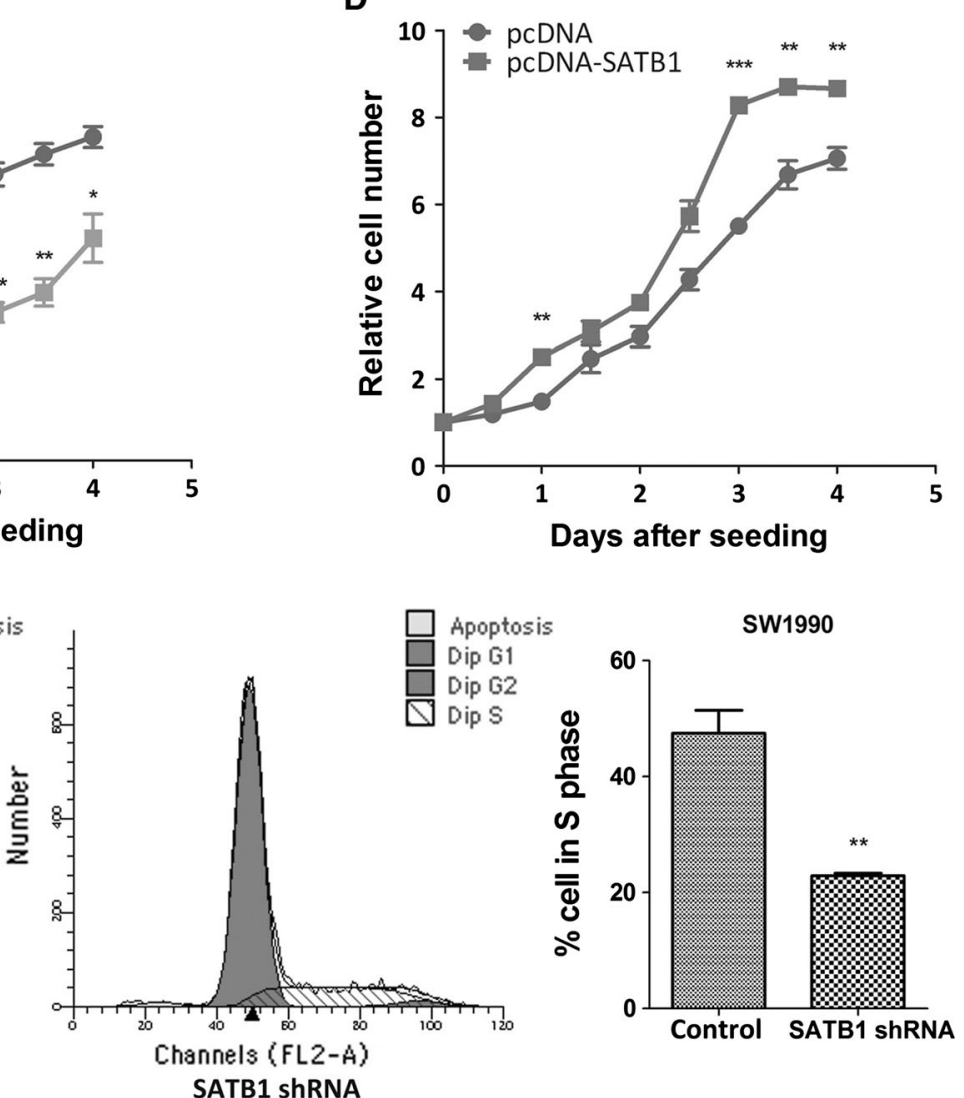

Fig. 2 Stably overexpression or knockdown of SATB1 regulates pancreatic cancer cell proliferation. a SATB1 expression level detected by PCR (left panel) and western blot (right panel) in SW1990 stably knockdown SATB1 (SATB1 shRNA) and control (control) cells. b SATB1 expression level detected by PCR (left panel) and western blot (right panel) in PANC-1 stably overexpressing SATB1 (pcDNA SATB1) or control (pcDNA) cells. c MTT cell

indicated that SATB1 regulates the expression level of MYC and MMP9 in pancreatic cancer cells.

\section{Blocking MYC Attenuates SATB1-Mediated Proliferation and Invasion in Pancreatic Cancer Cells}

To further study whether SATB1 promotes pancreatic cancer proliferation and invasion through the induction of growth curve analysis of SW1990 stably knockdown SATB1 or control cells. d MTT cell growth curve analysis of PANC-1 stably overexpressing SATB1 or control cells. e Cell cycle distribution analysis of control (left panel) or SW1990 stably knockdown SATB1 cells (middle panel) and quantification data (right panel). $* P<0.05$, $* * P<0.01, * * * P<0.001, t$ test

MYC, we knocked down MYC with MYC siRNA in PANC-1 stably overexpressing SATB1 or control cells. Western blot results demonstrated that the inhibition of MYC by siRNA-attenuated SATB1 induced the expression of MMP9 protein level (Fig. 5c) in PANC-1 stably overexpressing SATB1 cells. Cell growth curve and invasion assay analysis demonstrated that the knockdown of MYC expression using siRNA eliminated the stimulation of cell growth and invasion by SATB1 in PANC-1 stably 
Fig. 3 Stably overexpression or knockdown of SATB1 regulates pancreatic cancer cells growth and invasion. a EdU assay analysis of SW1990 stably knockdown SATB1 (SATB1 shRNA) or control (control) cells (left panel) and quantification data (right panel). b EdU assay analysis of PANC1 stably overexpressing SATB 1 (pcDNA SATB1) or control (pcDNA) cells (left panel) and quantification data (right panel) c Transwell migration/invasion analysis of SW1990 stably knockdown SATB1 or control cells (left panel) and quantification data (right panel) d Transwell migration/invasion analysis of PANC-1 stably overexpressing SATB1 or control cells (left panel) and quantification data (right panel), $* * * P<0.001, t$ test
A

SW1990
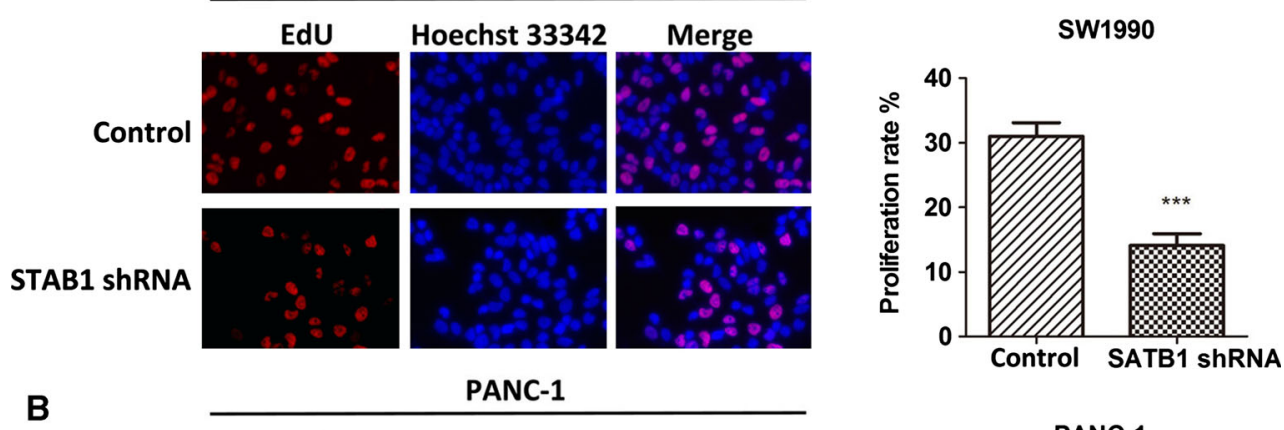

PANC-1

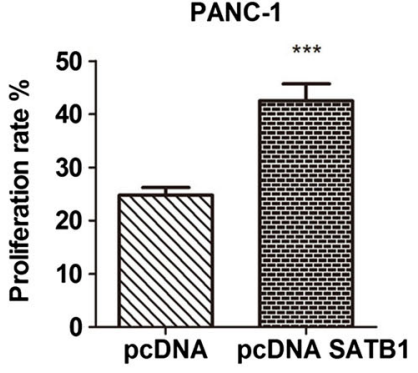

SW1990

C

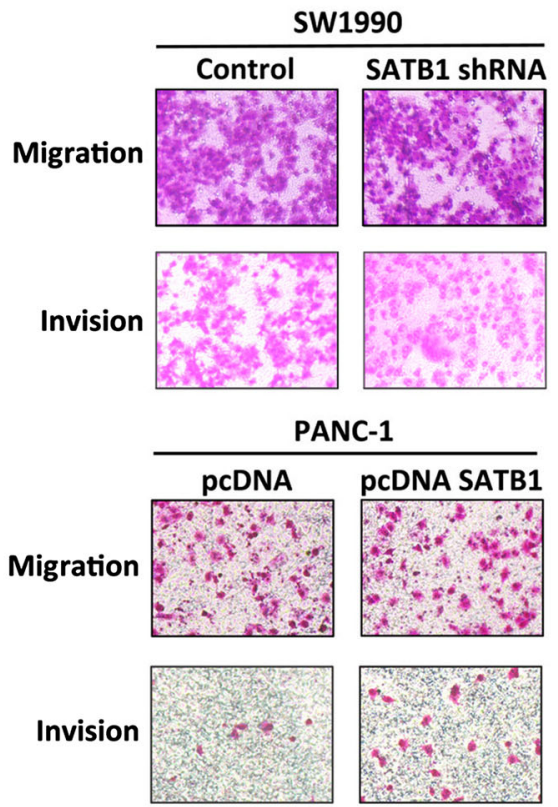

SW1990
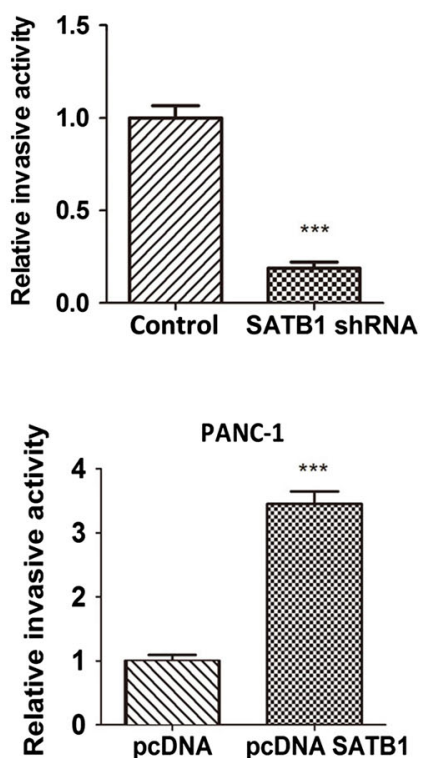

overexpressing SATB1 cells compared with control siRNA (Fig. 5d, e). Therefore, our results demonstrated: (1) SATB1 promoting pancreatic cancer proliferation and invasion through the induction of MYC; (2) the induction of MMP9 by SATB1 in pancreatic cancer was dependent on MYC induction; (3) SATB1-MYC-MMP9 axis played an important role in pancreatic cancer progression.

\section{SATB1 Binds to a Specific MYC Promoter Region Inducing MYC mRNA Expression}

To investigate whether SATB1 binds to MYC promoter regions, we analyzed MYC promoter activities in SW1990 stably knockdown SATB1 or control cells. Firstly, seven different lengths of MYC promoter regions ( $\mathrm{R} 1$ to $\mathrm{R} 7$, from -3090 to +100 ) were investigated using dual-luciferase reporter assay. The result showed that SATB1 knockdown significantly decreased luciferase activity in MYC promoter region $\mathrm{R} 1$ to $\mathrm{R} 3$ compared with control cells (Fig. 6a, b; $P<0.001$ ) but not in R4 to R7 (Fig. 6a). This indicated that MYC promoter region -2100 to -1567 contains SATB1 binding sites. Secondly, another six different lengths of MYC promoter regions (R8 to R13, from -2100 to -1560 ) were selected and examined to further identify the specific SATB1 binding sites in MYC promoter region. Our data indicated that the knockdown of 
A
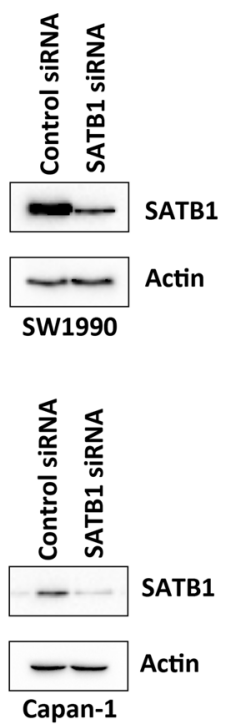

B

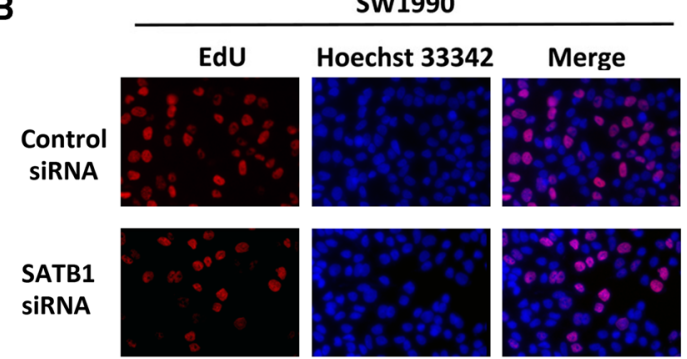

C

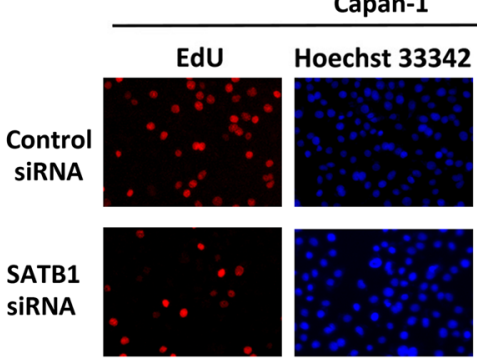

SW1990
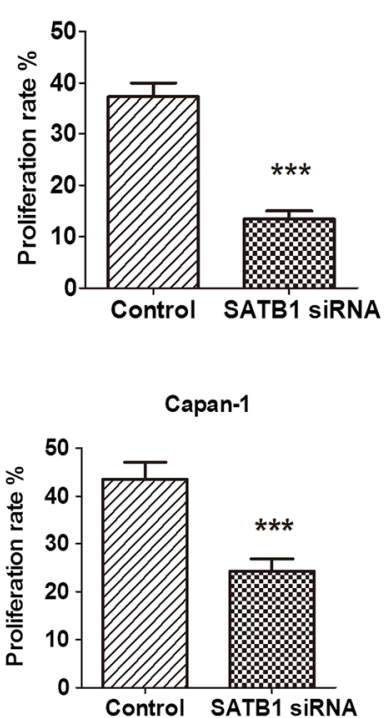
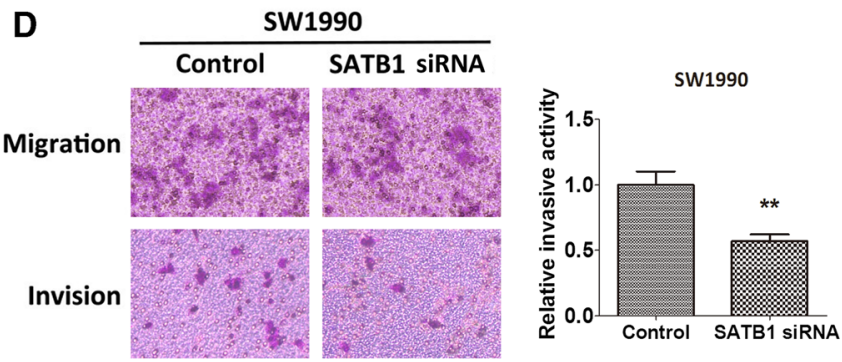

Fig. 4 Transiently knockdown SATB1 with siRNA decreases pancreatic cancer cells proliferation and invasion. a Western blot results showing SATB1 protein levels in PANC-1 (upper panel) or Capan-1 (lower panel) transiently knockdown SATB1 by siRNA or control cells. b, c EdU cell proliferation analysis of SW1990 or Capan-1

SATB1 decreased luciferase activity in MYC promoter region R8 to R11 compared with control cells (Fig. 6a, c; $P<0.001)$ but with no difference in R12 and R13. These results demonstrated that SATB1 binds to the specific MYC promoter region between -1774 and -1741 inducing MYC mRNA expression.

\section{Overexpression of SATB1 in Human Pancreatic Cancer Samples Correlates with Tumor Progression}

To examine whether SATB1 overexpression promotes human pancreatic cancer invasion and metastasis, we investigated the correlation between SATB1 expression and cancer clinic-pathologic features in 68 formalin-fixed paraffin-embedded pancreatic cancer tissue samples. Our analysis showed that SATB1 expression level was significantly higher in $\mathrm{T} 3+\mathrm{T} 4$ pancreatic cancer samples compared with $\mathrm{T} 1+\mathrm{T} 2$ samples in cancer invasion depth (Table $1, P=0.028$ ). In tumor staging, advanced
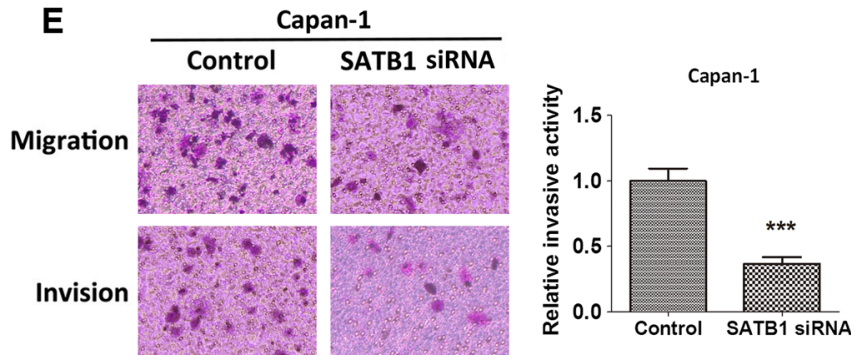

transiently knocking down SATB1 or control cells (left panels) with quantification data (right panels), ${ }^{* * *} P<0.001, t$ test. d, e Transwell migration/invasion analysis of SW1990 or Capan-1 knocking down SATB1 or control cells (left panels) with quantification data (right panels), $* * P<0.01, * * * P<0.001, t$ test

pancreatic cancer samples (stage II-III + stage III) expressed higher level of SATB1 than low staging samples (stage I + stage II) (Table $1, P<0.001$ ). These data clearly demonstrated that SATB1 expression level correlates with pancreatic cancer invasion and metastasis.

\section{Discussion}

Pancreatic cancer is the leading cause of cancer-related death in Western countries [36]. Although much work has been done to improve the diagnosis and treatment of this malignancy, it has proved difficult to inhibit its progression [37]. Adenocarcinoma cancer cells share common malignant biological properties. Same oncogenes or tumor suppressor genes and their associated signaling pathways may be involved in tumor formation from different organs, such as the TP53 gene or PI3K/AKT signaling pathways 

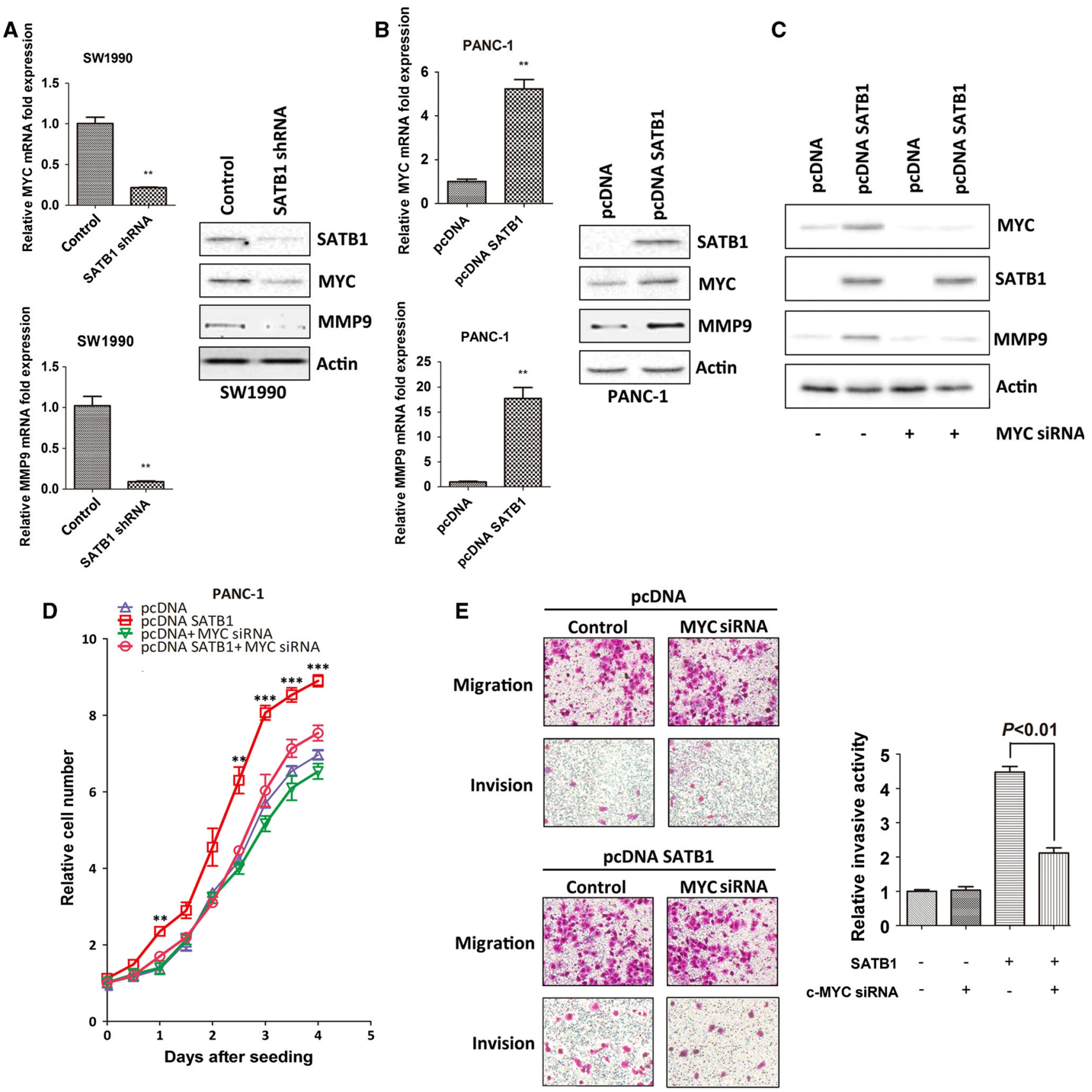

Fig. 5 SATB1 promotes pancreatic cancer proliferation and invasion dependent on MYC and MMP9 induction. a MYC and MMP9 mRNA or protein expression levels detected by qRT-PCR (left panels) and western blot (right panel) in SW1990 stably knockdown SATB1 (SATB1 shRNA) or control (Control) cells. b MYC and MMP9 mRNA or protein expression levels detected by qRT-PCR (left panels) and western blot (right panel) in PANC-1 stably overexpressing SATB1 (pcDNA SATB1) or control (pcDNA) cells. c Western blot analysis of MYC or MMP9 protein expression levels

in PANC-1 stably overexpressing SATB1 or control cells with or without MYC siRNA knockdown. d MTT cell growth curve analysis of PANC-1 stably overexpressing SATB1 or control cells with or without MYC siRNA knockdown, $* * P<0.01$, $* * * P<0.001$, compared with control cells, $t$ test. e Transwell migration/invasion analysis of PANC-1 stably overexpressing SATB1 or control cells with or without MYC siRNA knockdown (left panel) and quantification data (right panel), $P<0.01$, one-way ANOVA

[38-40]. Although SATB1 was first reported in breast cancer [16], we have identified it as a strong potential treatment target for pancreatic cancer.

In this study, we investigated SATB1 expression in pancreatic cancer cell lines and tissue samples. Our results demonstrated that SATB1 promotes pancreatic cancer 
A

MYC

Promoter
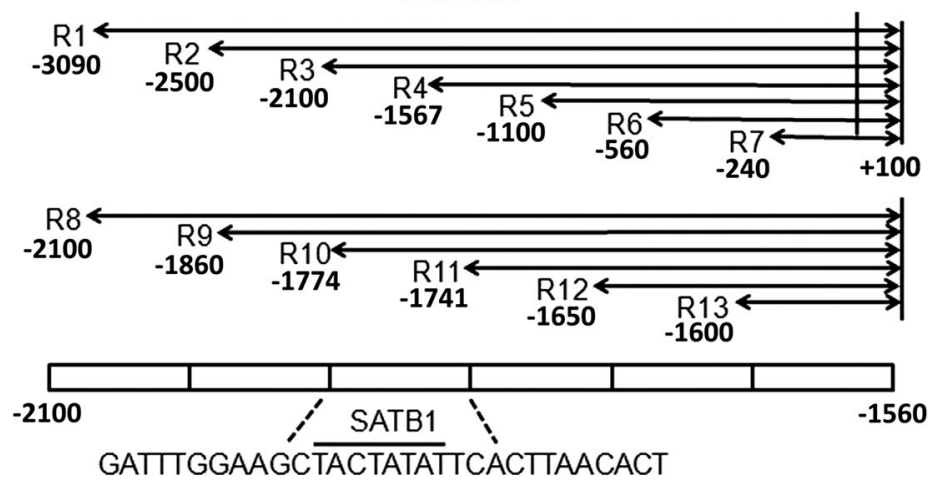

B

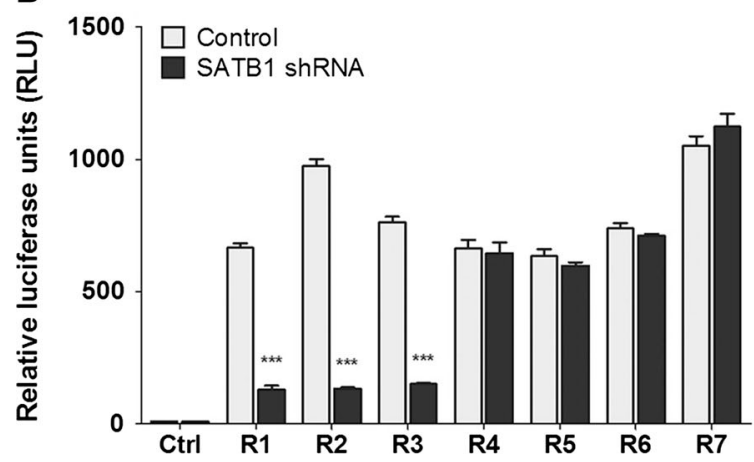

Fig. 6 Specific SATB1 binding sites localize in MYC promoter region. a Thirteen different lengths of MYC promoter regions were cloned into PGL3-basic reporter plasmid (upper panel). Localization of specific SATB1 binding site in MYC promoter region in pancreatic cancer cells (lower panel). b First round of luciferase MYC promoter reporter assay analysis in $\mathrm{R} 1$ to $\mathrm{R} 7 \mathrm{MYC}$ promoter regions in

proliferation and invasion through the regulation of MYC. This is supported by several lines of evidence: (1) We showed that SATB1 was overexpressed in pancreatic cancer cells and tissue samples; (2) SATB1 promoted pancreatic cancer cells proliferation and invasion depending on the induction of MYC; (3) using luciferase reporter assay, we found that SATB1 induced MYC expression by binding to a specific region of the MYC promoter; and (4) clinical data from human primary pancreatic cancer samples indicated that SATB1 was strongly correlated with tumor invasion depth and staging.

SATB1 was originally identified as a protein that binds to base-unpairing regions (BURs) of DNA [41], folding chromatin to regulate gene expression [12, 42]. SATB1 overexpression was observed in many kinds of human tumors, promoting cancer cells growth and metastasis by changing the gene expression profile [16, 43, 44]. Herein, we examined that the role of SATB1 plays in pancreatic cancer. Our data demonstrated that SATB1 was overexpressed in pancreatic cancer cell lines and tissue samples. And we further discovered SATB1
C

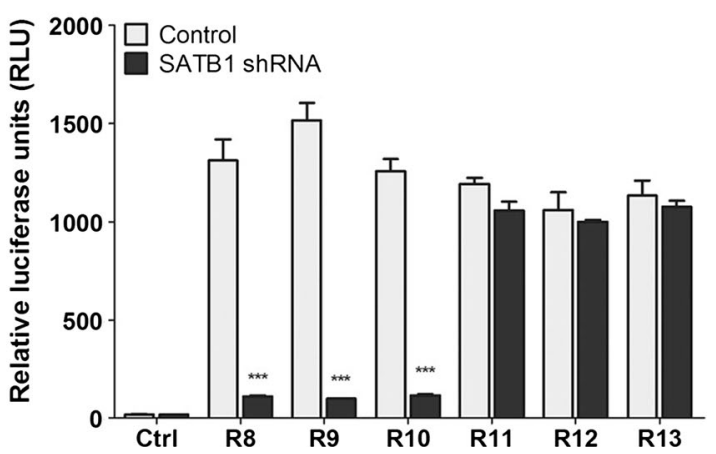

SW1990 stably knockdown SATB1 (SATB1 shRNA) or control (Control) cells. c Second round of MYC promoter reporter assay analysis in R8 to R13 MYC promoter regions in SW1990 stably knockdown SATB1 (SATB1 shRNA) or control (Control) cells. $* * * P<0.001, t$ test

significantly promoted pancreatic cancer cell proliferation and invasion. These results clearly indicated that SATB1 could be a promising target for inhibiting pancreatic cancer progression.

MYC overexpression and continued presence are associated with many human malignancies including pancreatic cancer, promoting cancer cells proliferation, invasion, angiogenesis, and metastasis [45-49]. MYC helps cancer cells to pass through the restriction point and progress from the $\mathrm{G} 1$ to the $\mathrm{S}$ phase [50]. And recently, a study has shown that SATB1 bound to -1531 to -1507 promoter sequence from the transcription start site of MYC gene [42]. MMP9 is a target of MYC, promoting cancer cells invasion and metastasis [51]. In this study, we investigated SATB1MYC-MMP9 axis in pancreatic cancer. Our results demonstrated that SATB1 regulates MYC and MMP9 expression in mRNA and protein levels, indicating that MYC or MMP9 could be direct downstream targets of SATB1. This is further confirmed by the results that knockdown of MYC significantly attenuated SATB1's oncogenic function and the induction of MMP9. Previous 
Table 1 Correlation of clinicpathological features of the patients with pancreatic cancer and SATB1 expression

\begin{tabular}{|c|c|c|c|c|}
\hline \multirow[t]{2}{*}{ Clinic-pathologic features } & \multirow[t]{2}{*}{ No. of cases } & \multicolumn{2}{|c|}{ SATB1 protein expression } & \multirow[t]{2}{*}{$P$ value } \\
\hline & & Positive & Negative & \\
\hline \multicolumn{5}{|l|}{ Age (year) } \\
\hline$<60$ & 26 & 17 & 9 & \\
\hline$\geq 60$ & 42 & 27 & 15 & 0.927 \\
\hline \multicolumn{5}{|l|}{ Gender } \\
\hline Male & 41 & 28 & 13 & \\
\hline Female & 27 & 16 & 11 & 0.446 \\
\hline \multicolumn{5}{|l|}{ Depth of invasion } \\
\hline $\mathrm{T} 1+\mathrm{T} 2$ & 13 & 5 & 8 & \\
\hline $\mathrm{T} 3+\mathrm{T} 4$ & 55 & 39 & 16 & $0.028 *$ \\
\hline \multicolumn{5}{|l|}{ TNM staging } \\
\hline $\mathrm{I}+\mathrm{I}-\mathrm{II}$ & 23 & 7 & 16 & \\
\hline II & 9 & 5 & 4 & 0.361 \\
\hline $\mathrm{II}-\mathrm{III}+\mathrm{III}$ & 36 & 32 & 4 & $<0.001 *$ \\
\hline \multicolumn{5}{|l|}{ Lymph node metastasis } \\
\hline Present & 26 & 19 & 7 & \\
\hline Absent & 42 & 25 & 17 & 0.256 \\
\hline \multicolumn{5}{|l|}{ Perineural invasion } \\
\hline Yes & 34 & 24 & 10 & \\
\hline No & 34 & 20 & 14 & 0.310 \\
\hline
\end{tabular}

$P$ value represents the probability from a Chi-square test for SATB1 expression in pancreatic cancer tissues studies suggested that SATB1 was identified as a protein that binds to gene promoters, regulating gene and protein expression levels [41, 52]. Our data indicated that SATB1 directly binds to a specific MYC promoter region, which identifying MYC as a downstream target of SATB1. A similar SATB1 binding sequence is reported in the human and mouse MYC promoter region [42]. Since SATB1 regulates gene expression in different ways by binding to the $5^{\prime}$ BURs [52], future studies could explore the further various molecular mechanisms of MYC regulation by SATB1 in pancreatic cancer.

A recent study indicated that the expression of SATB1 was an independent predictor of a significantly shorter recurrence-free survival and overall survival in pancreaticobiliary-type periampullary adenocarcinomas [53]. Our similar findings between SATB1 expression level and pancreatic cancer pathogenic-clinical features indicated that SATB1 was highly involved in cancer invasion and metastasis. Altogether, this is strong evidence confirming our in vitro results, showing that SATB1 promotes pancreatic cancer proliferation and invasion and plays a key role in tumor progression. Due to the difficulty in diagnosing pancreatic cancer in the early stage and the lack of effective treatment in the advanced stages of the disease $[54,55]$, our novel findings make SATB1 a potential therapeutic target of pancreatic cancer.

\section{Conclusions}

To our knowledge, these are the first results clearly demonstrating that SATB1 promotes pancreatic cancer cell proliferation and invasion through activation of MYC. The results elucidate the importance of SATB1 in understanding pancreatic cancer tumorigenesis, making SATB1 a promising therapeutic target for pancreatic cancer.

Acknowledgments This work was supported by the National Natural Science Foundation of China (No. 81072031 [BA10]) and Natural Science Foundation of Jiangsu Province (No. BK2010585).

Conflict of interest The authors declare that they have no conflict of interest.

Open Access This article is distributed under the terms of the Creative Commons Attribution-NonCommercial 4.0 International License (http://creativecommons.org/licenses/by-nc/4.0/), which permits any noncommercial use, distribution, and reproduction in any medium, provided you give appropriate credit to the original author(s) and the source, provide a link to the Creative Commons license, and indicate if changes were made.

\section{References}

1. Seino T, Nakadaira H, Endoh K, Yamamoto M. Changes in pancreatic cancer mortality, period patterns, and birth cohort 
patterns in Japan: analysis of mortality data in the period 1968-2002. Environ Health Prev Med. 2008;13:234-242.

2. Jemal A, Siegel R, Ward E, et al. Cancer statistics, 2008. $C A$ Cancer J Clin. 2008;58:71-96.

3. Greenlee RT, Hill-Harmon MB, Murray T, Thun M. Cancer statistics, 2001. CA Cancer J Clin. 2001;51:15-36.

4. Kuang TT, da Jin Y, Wang DS, et al. Clinical epidemiological analysis of the relationship between pancreatic cancer and diabetes mellitus: data from a single institution in China. J Dig Dis. 2009;10:26-29.

5. Lowenfels AB, Sullivan T, Fiorianti J, Maisonneuve P. The epidemiology and impact of pancreatic diseases in the United States. Curr Gastroenterol Rep. 2005;7:90-95.

6. Wahi MM, Shah N, Schrock CE, Rosemurgy AS II, Goldin SB. Reproductive factors and risk of pancreatic cancer in women: a review of the literature. Ann Epidemiol. 2009;19:103-111.

7. Nikolaev LG, Tsevegiyn T, Akopov SB, Ashworth LK, Sverdlov ED. Construction of a chromosome specific library of human MARs and mapping of matrix attachment regions on human chromosome 19. Nucleic Acids Res. 1996;24:1330-1336.

8. Liu JW, Tabe LM. The influences of two plant nuclear matrix attachment regions (MARs) on gene expression in transgenic plants. Plant Cell Physiol. 1998;39:115-123.

9. Barboro P, Repaci E, D'Arrigo C, Balbi C. The role of nuclear matrix proteins binding to matrix attachment regions (Mars) in prostate cancer cell differentiation. PLOS ONE. 2012;7:e40617.

10. Nakagomi K, Kohwi Y, Dickinson LA, Kohwi-Shigematsu T. A novel DNA-binding motif in the nuclear matrix attachment DNAbinding protein SATB1. Mol Cell Biol. 1994;14:1852-1860.

11. Galande S, Dickinson LA, Mian IS, Sikorska M, Kohwi-Shigematsu T. SATB1 cleavage by caspase 6 disrupts PDZ domainmediated dimerization, causing detachment from chromatin early in T-cell apoptosis. Mol Cell Biol. 2001;21:5591-5604.

12. Yasui D, Miyano M, Cai S, Varga-Weisz P, Kohwi-Shigematsu T. SATB1 targets chromatin remodelling to regulate genes over long distances. Nature. 2002;419:641-645.

13. Mao L, Yang C, Wang J, et al. SATB1 is overexpressed in metastatic prostate cancer and promotes prostate cancer cell growth and invasion. J Transl Med. 2013;11:111.

14. Li QQ, Chen ZQ, Xu JD, et al. Overexpression and involvement of special AT-rich sequence binding protein 1 in multidrug resistance in human breast carcinoma cells. Cancer Sci. 2010;101:80-86.

15. Han B, Luan L, Xu Z, Wu B. Expression and biological roles of SATB1 in human bladder cancer. Tumour Biol. 2013;34:2943-2949.

16. Han HJ, Russo J, Kohwi Y, Kohwi-Shigematsu T. SATB1 reprogrammes gene expression to promote breast tumour growth and metastasis. Nature. 2008;452:187-193.

17. Sun F, Lu X, Li H, et al. Special AT-rich sequence binding protein 1 regulates the multidrug resistance and invasion of human gastric cancer cells. Oncol Lett. 2012;4:156-162.

18. Meng WJ, Yan H, Zhou B, et al. Correlation of SATB1 overexpression with the progression of human rectal cancer. Int $J$ Colorectal Dis. 2012;27:143-150.

19. Lu X, Cheng C, Zhu S, et al. SATB1 is an independent prognostic marker for gastric cancer in a Chinese population. Oncol Rep. 2010;24:981-987.

20. Meyer N, Penn LZ. Reflecting on 25 years with MYC. Nat Rev Cancer. 2008;8:976-990.

21. Eilers M, Eisenman RN. Myc's broad reach. Genes Dev. 2008;22:2755-2766

22. Chen Y, Olopade OI. MYC in breast tumor progression. Expert Rev Anticancer Ther. 2008;8:1689-1698.

23. He C, Jiang H, Geng S, et al. Expression of c-Myc and Fas correlates with perineural invasion of pancreatic cancer. Int J Clin Exp Pathol. 2012;5:339-346.
24. Singhi AD, Cimino-Mathews A, Jenkins RB, et al. MYC gene amplification is often acquired in lethal distant breast cancer metastases of unamplified primary tumors. Mod Pathol. 2012;25:378-387.

25. Jang KY, Noh SJ, Lehwald N, et al. SIRT1 and c-Myc promote liver tumor cell survival and predict poor survival of human hepatocellular carcinomas. PLoS One. 2012;7:e45119.

26. Silva TC, Leal MF, Calcagno DQ, et al. hTERT, MYC and TP53 deregulation in gastric preneoplastic lesions. BMC Gastroenterol. 2012;12:85.

27. Aulmann S, Adler N, Rom J, Helmchen B, Schirmacher P, Sinn HP. c-myc amplifications in primary breast carcinomas and their local recurrences. J Clin Pathol. 2006;59:424-428.

28. Rummukainen JK, Salminen T, Lundin J, Joensuu H, Isola JJ. Amplification of c-myc oncogene by chromogenic and fluorescence in situ hybridization in archival breast cancer tissue array samples. Lab Invest. 2001;81:1545-1551.

29. Vandooren J, Van den Steen PE, Opdenakker G. Biochemistry and molecular biology of gelatinase B or matrix metalloproteinase-9 (MMP-9): the next decade. Crit Rev Biochem Mol Biol. 2013;48:222-272.

30. Fagan-Solis KD, Schneider SS, Pentecost BT, et al. The RhoA pathway mediates MMP-2 and MMP-9-independent invasive behavior in a triple-negative breast cancer cell line. J Cell Biochem. 2013;114:1385-1394.

31. Casimiro S, Mohammad KS, Pires R, et al. RANKL/RANK/ MMP-1 molecular triad contributes to the metastatic phenotype of breast and prostate cancer cells in vitro. PLoS One. 2013;8:e63153.

32. Alcantara MB, Dass CR. Regulation of MT1-MMP and MMP-2 by the serpin PEDF: a promising new target for metastatic cancer. Cell Physiol Biochem. 2013;31:487-494.

33. Kruger A, Kates RE, Edwards DR. Avoiding spam in the proteolytic internet: future strategies for anti-metastatic MMP inhibition. Biochim Biophys Acta. 2010;1803:95-102.

34. Zhu Y, Zhang JJ, Zhu R, et al. The increase in the expression and hypomethylation of MUC4 gene with the progression of pancreatic ductal adenocarcinoma. Med Oncol. 2011;28:S175-S184.

35. Remmele W, Stegner HE. Recommendation for uniform definition of an immunoreactive score (IRS) for immunohistochemical estrogen receptor detection (ER-ICA) in breast cancer tissue. Pathologe. 1987;8:138-140.

36. Parkin DM, Bray FI, Devesa SS. Cancer burden in the year 2000. The global picture. Eur J Cancer. 2001;37:S4-66.

37. Jemal A, Murray T, Samuels A, Ghafoor A, Ward E, Thun MJ. Cancer statistics, 2003. CA Cancer J Clin. 2003;53:5-26.

38. Wade M, Li YC, Wahl GM. MDM2, MDMX and p53 in oncogenesis and cancer therapy. Nat Rev Cancer. 2013;13:83-96.

39. Ma X, Hu Y. Targeting PI3K/Akt/mTOR cascade: the medicinal potential, updated research highlights and challenges ahead. Curr Med Chem. 2013;20:2991-3010.

40. Bitting RL, Armstrong AJ. Targeting the PI3K/Akt/mTOR pathway in castration-resistant prostate cancer. Endocr Relat Cancer. 2013;20:R83-R99.

41. Dickinson LA, Joh T, Kohwi Y, Kohwi-Shigematsu T. A tissuespecific MAR/SAR DNA-binding protein with unusual binding site recognition. Cell. 1992;70:631-645.

42. Cai S, Han HJ, Kohwi-Shigematsu T. Tissue-specific nuclear architecture and gene expression regulated by SATB1. Nat Genet. 2003;34:42-51.

43. Fang XF, Hou ZB, Dai XZ, et al. Special AT-rich sequencebinding protein 1 promotes cell growth and metastasis in colorectal cancer. World J Gastroenterol. 2013;19:2331-2339.

44. Chen H, Takahara M, Oba J, et al. Clinicopathologic and prognostic significance of SATB1 in cutaneous malignant melanoma. J Dermatol Sci. 2011;64:39-44. 
45. Ren J, Jin F, Yu Z, et al. MYC overexpression and poor prognosis in sporadic breast cancer with BRCA1 deficiency. Tumour Biol. 2013;34:3945-3958.

46. Hawksworth D, Ravindranath L, Chen Y, et al. Overexpression of C-MYC oncogene in prostate cancer predicts biochemical recurrence. Prostate Cancer Prostatic Dis. 2010;13:311-315.

47. Buchholz M, Schatz A, Wagner M, et al. Overexpression of c-myc in pancreatic cancer caused by ectopic activation of NFATc1 and the $\mathrm{Ca}^{2+} /$ calcineurin signaling pathway. Embo J. 2006;25:3714-3724.

48. Chen CH, Shen J, Lee WJ, Chow SN. Overexpression of cyclin D1 and c-Myc gene products in human primary epithelial ovarian cancer. Int J Gynecol Cancer. 2005;15:878-883.

49. Lin CP, Liu CR, Lee CN, Chan TS, Liu HE. Targeting c-Myc as a novel approach for hepatocellular carcinoma. World J Hepatol. 2010;2:16-20.

50. Mitchell KO, El-Deiry WS. Overexpression of c-Myc inhibits p21WAF1/CIP1 expression and induces S-phase entry in 12O-tetradecanoylphorbol-13-acetate (TPA)-sensitive human cancer cells. Cell Growth Differ. 1999;10:223-230.
51. Han G, Wang Y, Bi W. C-Myc overexpression promotes osteosarcoma cell invasion via activation of MEK-ERK pathway. Oncol Res. 2012;20:149-156.

52. Kohwi-Shigematsu T, Poterlowicz K, Ordinario E, Han HJ, Botchkarev VA, Kohwi Y. Genome organizing function of SATB1 in tumor progression. Semin Cancer Biol. 2013;23: 72-79.

53. Elebro J, Heby M, Gaber A, et al. Prognostic and treatment predictive significance of SATB1 and SATB2 expression in pancreatic and periampullary adenocarcinoma. J Transl Med. 2014;12:289.

54. Sarris EG, Syrigos KN, Saif MW. Pancreatic cancer: updates on translational research and future applications. JOP. 2013;14: 145-148.

55. Muller SA, Tarantino I, Martin DJ, Schmied BM. Pancreatic surgery: beyond the traditional limits. Recent Results Cancer Res. 2012;196:53-64. 